\title{
Best Practices for Healthy Estuaries
}

\author{
Hassan Badkoobehi, Pradip Peter Dey, and Mohammad Amin
}

\begin{abstract}
The economy of coastline areas depends on the natural splendor of estuaries. When estuaries are improperly managed or polluted, long or short term damage to local economy or harm to local life forms can be caused. Estuaries are natural shelters for thousands of species such as birds, mammals, fish, crustaceans, insects, reptiles, and amphibians. The delicate balance of these life forms in estuaries requires careful planning for the benefit of all. The commercial value of estuaries is very important; recreational activities that people enjoy like boating, kayaking, windsurfing, swimming, bird-watching and fishing are marketable. Estuaries are national treasures with vital community and ecological resources. Years of estuarine environmental studies have produced extensive results that merit consideration. This study reviews research results from various sources and suggests best strategies for maintaining healthy estuaries in the current socioeconomic conditions. The main hypothesis is that many estuaries can be restored to their original healthy status in a cost effective manner with restoration or prevention plans suggested in published studies.
\end{abstract}

Index Terms-Environment, pollution, sustainability, wildlife.

\section{INTRODUCTION}

Healthy estuaries support all life forms in a delicate balance in sustainable socioeconomic conditions as long as the balance is not disturbed by unusual events or activities. This study reviews research results from various sources and suggests best strategies for maintaining healthy estuaries. The main focus of this work is to learn from other studies and replicate successful strategies from analysis of the environmental situation and socio-economic estuarine systems using methodologies that allow identification, modeling and prioritization of problems and documentation and selection of indicators for a diagnosis of the situation and the design and implementation of systems for monitoring and intervention strategies for restoration and maintenance [1]-[4]. Detailed comprehensive environmental studies are often needed so that attention is paid to all aspects and important actionable data are properly analyzed. However, comprehensive scientific studies are expensive and resources are often difficult to obtain. Limitation of resources is an important motivation for reviewing other completed studies and learning from their successful applications. We hope to find successful strategies that can be replicated in many estuarial problems. Every study of estuaries must consider the influence of human activities on the environment, including demographic, economic, and social issues associated with the

Manuscript received November 22, 2014; revised January 8, 2015.

The authors are with National University, School of Engineering and Computing, 3678 Aero Court, San Diego, CA 92123, USA (e-mail: hbadkoob@nu.edu,pdey@nu.edu,mamin@nu.edu). process of development. In addition to human activities, other species of birds, fish, reptiles, amphibians, etc. need to be taken into account. The combined impact of animals and plants in the context of the hydrodynamic process in estuaries and the resulting changes in the total ecosystem must be studied before generating action plans. An estuary is a semi-closed costal water-body that is freely connected to the open sea allowing the sea water of the area to be measurably diluted with fresh water derived from land drainage [5]. "Estuaries are the most productive ecosystems on earth, containing more life per square inch than the lushest rainforest canopy" [6]. The biodiversity of estuaries is one of the most important well-known features of coastal areas. This report aims to provide a brief description of the ecological system of the estuaries, highlighting the interplay among the various factors such as biological, physicochemical, climatological, oceanographic, and socioeconomic aspects and the delicate balance needed for sustainability.

\section{BACKGROUND}

Published research studies provide valuable information about problems faced in various estuaries and some of the successful corrective measures or interventions. Often these studies elaborate on the corrective measures with sufficient details making it possible to replicate the measures in a new problem situation. We can extract enough information adequately from these studies so that expensive new studies can be avoided. Instead of conducting a new study, we hope to be able to find enough indications as to how to apply preventive and restoration measures from past studies. The benefits of mangroves and estuarine ecosystems comprise a wide variety of goods, services, applications and value functions for society, flora and wildlife as well as to maintain natural systems and processes. As natural systems control floods, hurricanes, erosion, and provide saline barriers, coastal protection, fisheries habitat, a haven for wildlife. In addition, formation of acid soils and toxins are also prevented. A positive correlation exist between the extent of the tidal zones (estuaries in the tropics) and the amount of fish and shrimp in the adjacent waters as observed in Malaysia, Philippines, Bangladesh, India, Louisiana and Japan [6]-[12]. Mangroves provide protection for predators and food for juvenile fish and crustaceans. Certain species of shrimps depend on mangroves for their juvenile stages. It is reasonable to infer that the decline of some shrimp forms is in direct proportion to the destruction of the mangroves [6]-[12]. There are reports that indicate that $85 \%$ of commercial fishing of shrimp, shellfish and species in Southern Florida dependent on the estuarine complex of Tampa Bay. In this region, where the $40 \%$ of mangroves have been destroyed from 1960 due to fillings for residential and commercial 
development, sport fisheries and commercial fisheries declined from \$ 575 million to \$ 10 million annually and the substantial decline of shorebirds in Southern Florida, attributing mainly to the cause of freshwater and marine wetlands loss [6]-[12]. Turner estimated an annual loss of 767 $\mathrm{kg}$ shrimp and commercial fish by each hectare of mangrove forest destroyed [7]; he argues that the value of mangroves support as fisheries habitat is more important than any other use, including the aquaculture. A 50\% decline of shrimp catch in certain areas from 1964 is due to the loss of $50 \%$ of its mangroves [6]-[12]. There are many economic implications. Tourism associated to Caribbean wetlands has resulted in a major source of income for many countries. Based on recent data, direct and indirect economic and environmental benefits of mangroves are estimated to be from $\$ 10,000$ to $\$ 125,000$ per hectare. Besides their ecological values, the mangroves have been used for centuries as energy source, construction material, salt extraction, dyes and even food. Despite the many benefits of mangroves, they have been affected by anthropogenic activities and consequently, there have been problems of water quality in adjacent water bodies showing an increase in turbidity, sedimentation, and eutrophication. Mangroves and other aquatic plants have been efficient and economical for maintaining healthy estuaries. Estuaries remove considerable amounts of nitrogen and phosphorus helping our environment. The mangroves and other wetland ecosystems support bio diversity, and function as temporary shelter of migratory birds and endangered species such as manatees (Trichechus manatus), some species of crocodiles (Crocrodylus moreletti) Jaguars (Thantera onca), etc. [12]. There have been improvements in areas of Florida after these are reforested with mangroves. The marshes and seasonal floodplains act as buffer zones reducing effects of floods and hurricanes in Florida and other areas. Approximately $78 \%$ of hurricanes in Pacific Coast of Mexico affect portions Southern and Central Sinaloa and the Southern tip of Baja California. The Army Corps of Engineers (1985) justifies conservation of floodplains to be among the most efficient systems for the economical flood control in the Coast of Gulf of Mexico [13].

In Mexico, mangroves have been damaged in various areas including Pacific coast. Initially, aquaculture represented a lack of coordination among the agencies involved in the management of coastal resources. Furthermore, the system for granting authorizations and farm construction is extremely complex and the shortage of inspectors makes enforcement and exercise of the law inadequate. These conditions have caused destruction of some mangrove areas (e.g. Marmol, Sinaloa in Mexico). During the last twenty years in Mexico, there has been about $12 \%$ deforestation of mangroves [14]. The second most important in terms of damage to mangrove forests in the Pacific Coast of Sinaloa, Mexico with 74,539 ha. However, the loss of mangroves is among the highest in the last 25 years or so [15]. Mangroves reforestation programs have been conducted successfully in various regions, including tropical Asian countries. The justifications for reforestation are diverse such as improving habitat to support fisheries, livestock as a food source, as a barrier against hurricanes, floods and protection against erosion by waves and tides, as a wildlife refuge, as a biological filter of contaminants, for aesthetic and even for reasons of military strategy [16].

A reforestation program requires careful planning involving a detailed knowledge of the available spaces of tidal zones, adjacent hydrological studies of the estuarine system, pattern and intensity of waves, grading and sediment chemistry and presence or absence of contaminants in water and sediments. The chemistry of the sediment, particularly salinity and the presence of sulfides are determinant factors for the successful colonization in the growth rate and developmental level of the mangrove forest. Another limiting factor in the proper growth of mangroves is the presence of certain pollutants, especially hydrocarbons and herbicides. Importantly, the mangroves are sensitive to changes in the flooding patterns that give net hydrological conditions of the combination of tides, contributions of pluvial/terrestrial runoff, precipitation-evaporation, wind effects, depth and geomorphology of the adjacent water body and topographic extension. Sometimes, health of mangroves may be affected by changes in the behavior of the adjacent body of water hydrodynamics. Floods and tidal variations can also cause substantial damage to life forms. Natural conditions of alteration of environmental parameters are reflected in the growth rings of trees. Ring information can be recovered and conveniently studied with ecological and environmental annual process [17].

It is a common belief that people act on their own self-interest. However, for a complex system it is often difficult to figure out how we benefit from such a system or to interact with it for our own best interest. This is one of the reasons for which we are often divided about complex systems. Estuaries are complex ecosystems with long and short term effects on us and other various life forms. Groups of humans may interact with the estuaries in many different ways and their interest may vary widely. Often our short term needs are so dire that we forgo our long term benefits. Socioeconomic conditions are often the most difficult part of a comprehensive study of complex systems of estuaries. However, long term benefits of restoring healthy estuaries need to be examined and socioeconomic aspects decision making have to be taken into account. Planning and management aspects of recovering ecosystems that have been degraded or destroyed need to be under focus. Wetlands have been the focus of many studies because during the last 200 years their health and sustainability have deteriorated significantly. For example, in the USA, we have less than $46 \%$ of the wetlands that existed upon the arrival of European immigrants [18]. Many wetlands were altered or drained to promote utilizations for agriculture, while others were filled for the urban development, surrounded with dikes to form ponds or slow the flood, or dredged to build marinas and ports. Indirect or direct effects of pollutants, runoffs and incursion by non-native species continued degradation and destruction of wetlands [4]. Undoubtedly, estuaries in our country are in serious danger. The indispensable habitats they provide for wildlife are shrinking. Job losses in the tourism, fishing and recreation industries are mounting with the loss of bio-diversity and unbalanced encroachments. Some of the consequences may pose a threat to wild life and human health. In many respects, the life style that has been in our coastal 
communities for generations is in danger today [19].

People often associate estuaries with the Nature's Bounty. In addition to food supplies, estuaries are home for thousands of different species of fish, birds, plants, and animals and their survival relies on healthy habitats. Job creation in areas close to estuaries is important for local economies. Around 28 million of jobs completely depend on healthy estuaries such as tourism, fishing, and recreational boating industries for their customers and products. In fact, the coastal water and estuaries provide major habitats for $80 \%$ to $90 \%$ of entertainment related fish and about $75 \%$ of America's commercial fish [19]. Estuaries that are kept healthy will keep the unique local traditions and cultures alive for decades. In order to keep these ways of life for the next generation, estuaries must be restoring. Expand the entertainment value of estuaries. In 1993, 180 million American, about 70\% of American people visited estuaries for enjoyment, sport, vacation, or tourism. Humans spend their time for viewing the wildlife of the estuaries, boating, fishing, hunting, roaming, hiking, and swimming. To keep this high percentage of visitors who want to experience their exciting activities in estuaries, appropriate management of estuaries should be emphasized.

The quality of life near estuaries can be improved by taking proper care of estuaries. About 110 million Americans live near estuaries. They are dependent on healthy estuaries and wildlife habitats provided in them. Estuaries help our children to learn; because people visit estuaries with their family. Estuaries should be considered as scenic educational sources that must be kept as a laboratory for living things [19]. Years of estuarine environmental research have educated researchers and scientists good facts about estuaries. In many studies, the levels of damage and the requirements of restoring them are clearly outlined. We need to know more about them, but we can apply what has been learned from these studies. Engineers and scientists can design a plan for restoring the structure and organization of estuaries, like vegetation, wildlife, and water flow manner in order to correct a damaged situation.

\section{STRATEGIES AND MANAGEMENT}

The strategies and methods used for assessing environmental and socio-economic damages to wetlands and inhabitants and restoration methods are based on current best practices [20], [21]. The methods are based on a comprehensive evaluation to identify causes and priorities for remedial and mitigation actions, designed to achieve significant environmental benefits. Often, human activities or some alterations of the environment affect the main aspects of the coastal zones; the activities are typically agricultural productions, livestock, business or shopping centers, industrial production, infrastructure, and other developmental work and services.

The first method to consider for the renovation of the functions of a wetland is to remove the factors causing the degradation or loss of wetland and let nature do the work of restoring the wetland. This method is often known as the passive strategy [4]. Thus, if the vegetation and water quality of a wetland are degraded mainly due to livestock grazing, then adequate strategies need to be developed for removing the livestock in order to restore the healthy ecosystem. Passive strategies are designed for natural regeneration of communities of plants, fish and wildlife forms. Passive strategies can be adequately applied if degraded site retains the fundamental natural features of the wetland and the source of degradation is an action that can be reversed [4]. In some places, passive methods are not sufficient to obtain the changes required for restoration; therefore, some active strategies may be required. Active strategies are designed for planned physical intervention in which authorized human participants directly control planned procedures and processes in place in order to restore, generate, or improve the wetland system. Active strategies are appropriate when a wetland is radically degraded or when the restoration objectives cannot be achieved in any other way. Active methods include alteration of the outline of an effected area in order to get the desired topography, shifting the water flow by means of controlled structures such as dams or drains, active planting, seeding, and strict control of nonnative species. In this paper, we describe four phases of a wetland management process with a focus on restoration, generation, or improvement: planning, implementation, monitoring and long-term management.

\section{A. Phase I: Planning}

Proper planning is a critical factor in the process of restoration, conservation, and improvement. An inadequate planning is often cited as one of the main reasons why projects fail to achieve functional goals. Here are some reasons why good planning is important: (1) A good plan makes connections between goals and activities. (2) A plan requires the collection of information on the local area, potential sites for restoration, generation or enhancement and historical trends [4]. (3) A plan is a documented repeatable method for identifying the materials, tasks, and activities required to achieve the goals of the project. The restoration project design, generation, or improvement can be highly technical and may require expert hydrologists, ecologists, geotechnical, and/or landscape architects.

\section{B. Phase II: Implementation}

The implementation consists of the physical process of carrying out the management plan based on the approaches to restoration, protection, or enhancement of wetlands according to the planning stage. This phase requires a series of steps that depend on wetland type, goals and objectives and the current state of the wetland. These steps may include but not limited to: (1) Preparation of the site: The preparation may include removal of garbage, rubbles, non-native species, cleaning of drains, fencing livestock, etc. (2) Carrying out the actions of the plan: Many activities can be conducted at this stage to improve, protect, or restore a wetland, all of which should be clearly defined and explained in the plan developed at the planning stage. Some examples of actions are: the construction of water control structures, construction of available habitats for biodiversity, placing new soil in affected sections, planting seedlings or seeds of native species. Mangrove restoration can be performed using reforestation and hydrologic restoration. Both require careful planning and local support. 


\section{Phase III: Monitoring}

Monitoring involves observation and collection of qualitative and quantitative data that provide information on changes that may indicate problems and/or progress toward specific goals or performance standards [4]. Monitoring allows early detection of emerging problems and cost effective remedial measures. One may argue that once a project has been implemented, the nature will do the rest by automatically regenerating diminishing the value of monitoring. In fact, many wetland projects require monitoring and planned corrective human efforts when things go wrong. If the monitoring process detects that previously planted seeds are washed away by a storm, then timely replanting seedlings may help. An effective monitoring method may also provide information on routine maintenance activities that may be needed to keep the target area running smoothly. Monitoring includes measuring various wetland traits or parameters at planned intervals to document changes in the characteristics of the wetland system. Monitoring efforts may be directly linked to specific goals [4]. The information obtained from monitoring can be used in many ways. First, the monitored data may indicate whether reasonable progress have been made towards achieving the intended goals of the project. Periodically, the data should be organized, and summarized in graphs and charts for review as the wetland system is being developed. Monitored data should be compared with expected standards to determine if the site is being developed appropriately. If not, some remedial measures should be applied or the original goals should be reevaluated. Second, monitored data may provide guidance about repeatability of the plan. That is, if any needs to be changed in case the same process is repeated in a similar situation. The monitoring data may help in the preparation of a process improvement proposal. Third, use long-term monitoring to assist in the maintenance of structures and site management to keep it running well. Finally, use the monitoring data to inform others such as local planning authorities and wetlands regulators, and local offices dedicated to conservation [4].

\section{Phase IV: Long-Term Management}

In order to maintain the delicate balance in the estuarine ecosystem, an adaptive long-term management scheme needs to be followed. Ad hoc temporary actions may not help much in maintaining sustainability. An agile approach to long-term management would enable continuous monitoring and adjusting all aspects of an estuarine restoration and maintenance project [22]. In addition to providing data on whether a wetland site is being developed appropriately, monitoring is crucial for long-term management of various aspects of the project. An estuarine coastal area usually represents an ecosystem that fluctuates and evolves in response to the changes in the surrounding environment. For socioeconomic reasons, human activities may change rapidly in any area impacting nearby wetlands. It is unrealistic to expect that after the completion of the project implementation phase, the task is finished. The long-term management is often required to keep the estuarine site safe from human impacts. Restoration and maintenance of wildlife diversity may require a long-term management scheme in place. For example, the long-term management is often needed for several activities, including maintaining vegetation, wildlife forms, and existing structures such as dams and dikes. On way to have an active long-term management is to involve local organizations and communities. To keep the human encroachments in check, long-term management may include periodic educational events, such as workshops, excursions and educational trips. Since natural systems may vary widely, it is reasonable to plan for a wide range of possible targets instead of having a narrowly defined target. For example, the site may be in the process of recovery by developing a new natural inborn wetland community, although not the same as planned. If this new community is within the rules of the type of wetland then it should be acceptable. The long-term management strategies should be designed to compensate for changes in the surrounding areas. The use of land in the vicinity, hydrology or other characteristics of the local area may change over time, possibly impacting the nature of the wetland area. Long term strategies are designed to mitigate the negative impacts of these changes. Some natural changes can be anticipated in many sites; adapting to these changes needs effective planning. If some radical unanticipated changes occur, then the long term plan may be revised dynamically to deal the changes. It is important to make plans although the plans may have to be changed dynamically based on circumstantial reasons. What is needed is an agile approach to long term planning [22] in order to deal with changes. Most of the harmful changes are caused by wrongly motivated human activities. An agile approach to long term planning and management would be appropriate for dealing with such activities. The overall goal of long-term management is a good natural wetland to provide exceptional performance and values within the context of the landscape and requires minimum human intervention. Finally, an agile plan for long-term management is needed to identify who will be the responsible for what aspect of the site and what kind of activities should be permitted [4], [22].

\section{CONCLUSION}

The first step in managing any natural resource is to assess its current status and to spot any existing threats to its health. The impact of economic, social and environmental aspects of development on coastal ecosystems is undeniable. Causes of problems and symptoms can be established and remedial actions can be taken in a timely manner. Past studies suggest that prevention and restoration are possible through adopting proven measures. Reforestation and hydrologic restoration can be achieved through careful planning and local support. Eventually, five priority problem areas need to be examined: water quality, living resources, environment management, human uses, education and public involvement. In each of the areas, factors that caused the problem need to be addressed. Often information needs to be analyzed in order to decide as to which actions can be taken. If the causes cannot be established easily, then a detailed study needs to be conducted with appropriate models and quantification. The prevailing management framework at the native, state, and federal levels needs to be identified for determining future action plans. In a number of cases, a detailed new study would not be needed. That is, restoration and prevention measures can be taken 
without new studies if studies of similar problems from a comparable problem situation can be identified.

\section{ACKNOWLEDGMENT}

The authors gratefully acknowledge the helpful contributions from Milan Jose Carlos, Basmal Hana and Fadi Zaco. In addition, authors are thankful for comments and/or encouragements received from John Cicero, Bhaskar Raj Sinha, Gordon Romney, Jodi Reeves, M.S. Jose J. Velazquez, M.S. Napoleon Gudiňo, and many others during the preparation of this paper and/or the research reported in it.

\section{REFERENCES}

[1] K. R. Dyer, Estuaries: A Physical Introduction, 2nd ed., Wiley, 1998.

[2] Z. Ji, Hydrodynamics and Water Quality: Modeling Rivers, Lakes, and Estuaries, Willey, 2008.

[3] D. Prandle, Estuaries: Dynamics, Mixing, Sedimentation and Morpholog, Cambridge University Press, 2011.

[4] The Interagency Workshop on Wetland Restoration: National Oceanic and Atmospheric Administration, Environmental Protection Agency. (May 12, 2012). Army corps of engineers, fish and wildlife service, and natural resources conservation service, an introduction and user's guide to wetland restoration, creation, and enhancement. [Online]. Available: http://water.epa.gov/type/wetlands/restore/finalinfo.cfm and http://catalogue.nla.gov.au/Record/3828217

[5] D. Pritchard, Observations of Circulation in Coastal Plain Estuaries. In Estuaries, American Association for the Advancement of Science, Washington, D.C., no. 83, pp. 37-44, 1967.

[6] Peconic Estuary Program, Protecting \& Restoring Long Island's Peconic Bays. (May 15, 2012). [Online]. Available: http://peconicestuary.org/about.php

[7] R. E. Turner, "Factors affecting the relative abundance of shrimp in Ecuador," A Sustainable Shrimp Mariculture Industry for Technical Report Series TR-E-6, pp. 121-139, 1991.

[8] M. Nuruddin, "Effects of shrimp farming and other impacts on mangroves of Bangladesh," presented at Workshop on Strategies for the Management for Fisheries and Aquaculture in Mangrove Ecosystems, 1987.

[9] W. Macnae, "Mangrove forest and fisheries," FAO/UNDP Indian Ocean Fishery Programme, IOFO/Dev/7434. FAO, Rome, 1974.

[10] W. N. Lindall, J. Hall, J. E. Sykes, and E. L. Arnold, "Louisiana coastal zone: Analysis of resources and resource development needs in connection with estuarine ecology. Sects. 10 and 13-Fishery Resources and Their Needs," Report of the Commercial Fishery Work Unit, Natl. Mar. Fish. Serv. Biol. Lab., St. Petersburg Beach, Florida, 1972.

[11] W. N. Lindall, J. Hall, W. A. Fable, and L. A. Collins, A Survey of Fishes and Commercial Invertebrates of the Shore and Estuarine Zone between Cape Romano and Cape Sable, Florida, Springfield, Va.: National Marine Fisheries Service, U.S. Department of Commerce, 1973.

[12] W. N. Lindall and C. H. Saloman, "Alteration and destruction of estuaries affecting fishery resources of the Gulf of Mexico," Marine Fisheries Review39, pp. 1-7, 1977.

[13] P. R. Burbrige, "Coastal resource management, government of Indonesia-United Nations development program, environmental sector review," United Nations Development Program, Jakarta, 1982.

[14] H. E. Daugherty, "Human impact on the mangrove forests of El Salvador," in Proc. Int. Symp. Biol. Manage. Mangroves, October 8-11, 1974, p. 816.

[15] F. Flores-Verdugo, F. González-Farías, O. Ramírez-Flores, F Amezcua-Linares, Yáñez-A. Arancibia, M. Alvarez-Rubio, and J. W. Day, "Mangrove ecology, aquatic primary productivity, and fish community dynamics in the Teacapán-Agua Brava Lagoon-Estuarine system (Mexican Pacific)," Estuaries, vol. 13, no. 2, pp. 219-230, 1990.

[16] J. W. Day, W. G. Smith, P. R. Wagner, and W. C. Stone, Community Structure and Carbon Budget of a Salt Marsh and Shallow Bay
Estuarine System in Louisiana, Center for Wetland Resources, Louisiana State University, Baton Rouge, no. LSU-SG-72-04, 1973.

[17] H. C. T. Manglares, Lagunas costeras y el Litoral Mexicano, Universidad Autonoma de Baja California Sur., pp. 371-425, 1991.

[18] H. C. T. Manglares, Lagunas Costeras y el Litoral Mexicano, Univ. Auton. de Baja California Sur., pp. 371-423, 1994.

[19] Proceeding of Restore America's Estuaries $6^{\text {th }}$ National Conference (2012). [Online]. Available: http://www.estuaries.org/conference-2012-proceedings.html

[20] Global International Waters Assessment. (February 10, 2013). Challenges to International Waters; Regional Assessments in a Global Perspective. [Online]. Available: http://www.unep.org/dewa/giwa/publications

[21] Global International Waters Assessment. (2012). Methodological guide of the global international waters assessment. [Online]. Available: http://www.unep.org/dewa/giwa/publications/ February 2013.

[22] J. J. Lawler "Climate change adaptation strategies for resource management and conservation planning," Annals of the New York Academy of Sciences, vol. 1162, pp. 79-98.

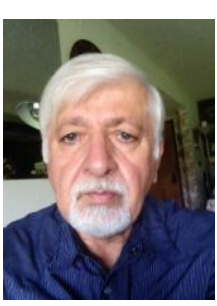

Hassan Badkoobehi is a professor at National University in the School of Engineering and Computing at 3678 Aero Court, San Diego, CA, 92123 USA. His major research interests are environmental engineering, mathematical and statistical reasoning, industrial engineering, computational models, and engineering education. He has done an M.S. degree in industrial engineering in 1978 and a Ph.D. degree in engineering in 1982 from the University of Oklahoma, USA.

He teaches mathematics, statistics, sustainability and engineering courses at National University. He has published more than 40 papers in journals and conference proceedings. He holds a P.E. license in California, USA.

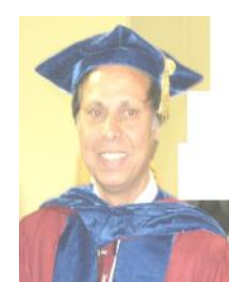

Pradip Peter Dey is a professor at National University, 3678 Aero Court, San Diego, CA, 92123 USA. He is a faculty leader for the M.S. in computer science program at the School of Engineering and Computing. His major research interests are computational models, software design, mathematical reasoning, environmental engineering, user interfaces and computer science education. He did his M.S.E. degree in computer science in 1982 from the University of Pennsylvania, Philadelphia, USA. He did an interdisciplinary Ph.D. degree in 1984 from University of Pennsylvania, Philadelphia, USA.

$\mathrm{He}$ teaches computer science and software engineering courses at National University. He has more than 20 years of teaching experience. $\mathrm{He}$ has taught artificial intelligence, compiler construction and natural language processing at several US universities. He has published more than 50 papers in various journals and conference proceedings. Dr. Dey is a member of the Association of Computing Machinery (ACM).

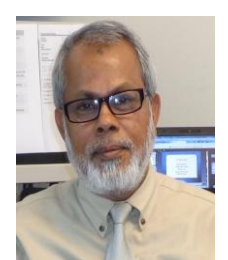

Mohammad Amin is with National University, 3678 Aero Court., San Diego, CA, 92123, USA. He is a professor and a faculty leader for the M.S.E.E. degree program at the School of Engineering and Computing at National University. His major research interests are computational modeling, wireless communications, databases, sensors and engineering education. He received his $\mathrm{Ph} . \mathrm{D}$. degree in electrical and computer engineering in 1997, M.S. degree in electrical and computer engineering in 1996, and M.S. degree in physics in 1985 from Marquette University, Milwaukee, Wisconsin, USA

He teaches both graduate and undergraduate levels engineering and computer science courses in the School of Engineering and Computing at National University. He holds three US patents. He has published more than 20 journal articles, and 70 papers in conference proceedings. Dr. Amin is a member of the ASEE (American Society of Engineering Education), Eta Kappa Nu (EE Honor Service), Sigma Xi, the Scientific Research Society and Biocom. 